\title{
Axon reflexes in human motor nerve fibres
}

\author{
PAMELA M. FULLERTON ${ }^{1}$ AND R. W. GilliatT \\ From the Institute of Neurology, Queen Square, London
}

、Partial denervation of muscle is followed by collateral sprouting of surviving nerve fibres close to their

1. terminations. The histological evidence for this process in animals has been reviewed by Edds (1953), and full references to the early animal experiments in this field are given in his paper. Collateral sprout-

- ing in human muscle was first described by Coërs (1955) and by Wohlfart (1955) and has been the

subject of much recent work, notably by those who have used methylene blue to stain the terminal innervation in muscle specimens taken at biopsy (Coërs

, and Woolf, 1959; Harriman, 1961). Collateral sprouting of intramuscular nerve fibres has the effect

rof incorporating denervated muscle fibres into sur-

$\sim$ viving motor units. This results in an increase in the

- amplitude of motor unit action potentials (Yahr, Herz, Moldaver, and Grundfest, 1950) and an increase in motor unit territory (Erminio, Buchthal, and Rosenfalck, 1959).

The studies described above were mainly concerned with the terminal parts of the intramuscular nerves, and the evidence for collateral sprouting in

- the proximal parts of nerve fibres is much less satisfactory. Edds himself failed to find any evidence of

- this in the rat; his technique was to divide one of the roots contributing to the sciatic nerve and then to

" carry out total counts of myelinated fibres at different

levels of the nerve trunk. Subsequently Causey and

- Hoffman (1955) repeated these experiments using the electron microscope to demonstrate fine nonmyelinated fibres. By this technique they observed , collateral sprouts growing out from surviving fibres, but were doubtful whether these ever made functional

- connexion with muscle. By means of silver staining, Wohlfart (1958) also demonstrated fine collateral

sprouts in the nerve trunks of patients with poliomyelitis and motor neurone disease. These collaterals

appeared to remain immature even in patients whose

- poliomyelitis had occurred many years before, and it was considered unlikely that such sprouts ever succeeded in reinnervating muscle fibres.

After division of a peripheral nerve, however, it is

- known that regenerating nerve fibres produce many branches, particularly at the site of injury (Ramón y

- Cajal, 1928). Quantitative studies have been carried In receipt of a personal grant from the Medical Research Council. out by Shawe (1955) who estimated that after nerve crush in the rabbit the fibre content of the distal nerve trunk was increased by $50 \%$ compared with nerve above the crushed segment. References to the branching of regenerating nerves distal to the point of injury may be found in the works of both Ramón y Cajal (1928) and of Nageotte (1932), but the exact site at which this occurs and the extent to which this results in the reinnervation of muscles is not clearly stated.

It is the purpose of this paper to present electrophysiological evidence for the proximal branching of motor nerve fibres in patients with chronic partial denervation. The investigation arose from the chance finding of what appeared to be an axon reflex ${ }^{2}$ elicited by the electrical stimulation of a motor nerve; similar responses were later found in other patients in sufficient numbers to suggest that this is a relatively common phenomenon.

\section{MATERIAL AND METHODS}

Twenty-five patients with lower motor neurone lesions affecting the hand were examined. The first patient in whom the characteristic abnormality was seen had a brachial plexus lesion due to a cervical rib, and initially it was thought that the phenomenon might result from branching at the level of the lesion. Other patients with cervical ribs were therefore studied before it was realized that branching might occur below the level of the lesion; this explains the high proportion of patients with cervical ribs in our series (Table III). Eight patients with ulnar nerve lesions at the elbow were also studied, as well as three patients with neuropathy of the Guillain-Barré type and one patient with diabetic neuropathy. Five patients with motor neurone disease completed the series. All patients showed wasting and weakness of the hand muscles selected for examination.

In order to avoid the effects of low temperature on conduction velocity, the arm to be examined was placed in hot water for five minutes before each session. The patient was then covered with blankets, the arm itself being wrapped in cotton wool. Skin temperature was recorded from the region of the stimulating cathode and was usually between $34^{\circ}$ and $36^{\circ} \mathrm{C}$.

'The term 'axon reflex' is usually employed in relation to sympathetic or sensory fibres but similar reflexes have been described in motor fibres by Hunt and Kuffier (1954). The term is used here to indicate conduction of an impulse up one branch of a motor axon to the point 
Motor fibres to the small muscles of the hand were stimulated through a cathode placed on the skin over the course of the median or ulnar nerve at the wrist, the anode being a metal plate on the dorsum of the wrist or forearm. The stimulus was a condenser discharge with a timeconstant of $100 \mu \mathrm{sec}$, delivered through a 1:1 isolating transformer, the output impedance being $500 \mathrm{ohms}$. Stimulus voltage was continuously variable up to $300 \mathrm{~V}$. For convenience the stimulator was set to repeat at one second intervals, except on the occasions mentioned in the text when repetitive trains at higher frequency were used. When pairs of shocks were required to measure refractory periods, two stimulators were used as described by Gilliatt and Willison (1963). Pulses from a digital timing unit (Pitman, 1958) were used to trigger the stimulators and the oscilloscope sweep. It was therefore possible to display late events on a fast sweep, thus improving the accuracy of latency measurement for potentials occurring 15-30 msec. after the stimulus. An example of this is shown in Figure 10.

Muscle action potentials were recorded from abductor pollicis brevis, abductor digiti minimi, or the first dorsal interosseous muscle, through either surface or coaxial needle electrodes. For surface recording, the active electrode was placed over the most prominent part of the muscle belly and the remote electrode over the tendon at the base of the digit. Muscle action potentials were amplified, displayed on a cathode ray tube and photographed, the apparatus and technique being similar to those described in previous papers (for references see Fullerton, 1963, 1964).

\section{RESULTS}

LATENCIES OF THE $M$ AND F WAVES When the median or the ulnar nerve in a healthy subject is stimulated at the wrist and the muscle action potential recorded from one of the small muscles of the hand, the direct response or $\mathbf{M}$ wave is followed by a much smaller deflection known as the $F$ wave (Magladery and McDougal, 1950). The latency of the $M$ wave represents the conduction time from wrist cathode to muscle, and varies with the particular hand muscle examined and the site and type of recording electrode used. Values of 2 to $4 \mathrm{msec}$. have been obtained with surface electrodes (Carpendale, 1956; Fullerton, 1963) whereas coaxial needle records have given slightly higher values (Ebeling, Gilliatt, and Thomas, 1960; Thomas, 1960).

Originally it was thought that the $\mathrm{F}$ wave was due to a reflex response caused by stimulation of rapidly conducting muscle afferent fibres, but recently it has been established that it is due, at least in part, to antidromic excitation of motoneurones by the ascending volley in motor fibres. This was first suggested by Dawson and Merton (1956) on the basis of experiments in man, and it has recently been confirmed by Wiesendanger and Gassel (1964) in the cat. When recorded through surface electrodes (an
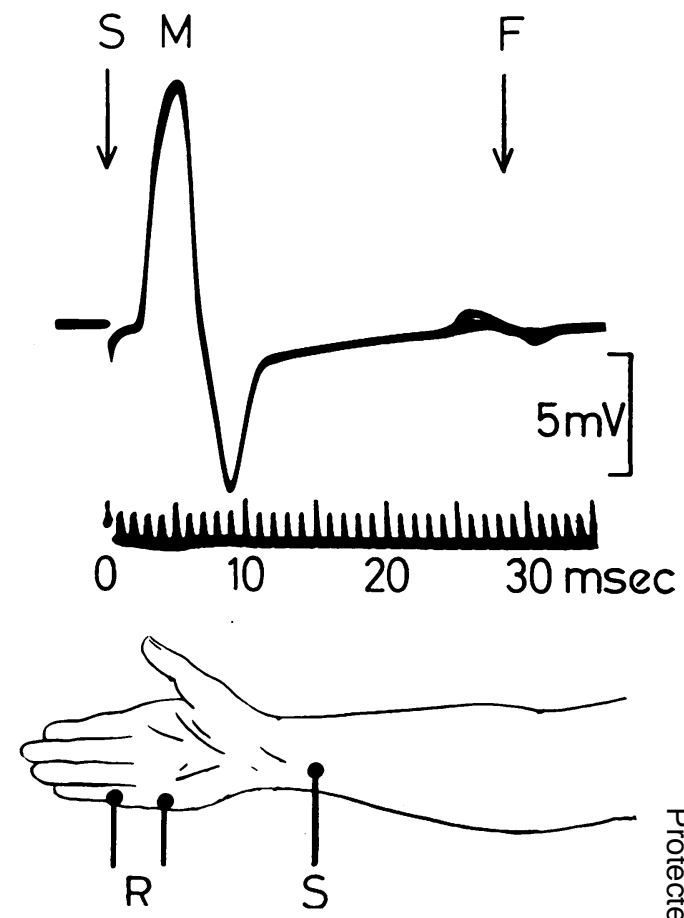

FIG. 1. Control subject. Normal $M$ and $F$ waves recorded from abductor digiti minimi through surface electrodes: Stimulus to the ulnar nerve supramaximal for motor fibణิ Five consecutive traces superimposed.

active electrode over the muscle belly against $a^{\mathrm{T}}$. remote electrode over the tendon), the amplitude of the $\mathrm{F}$ wave is rarely more than $5 \%$ of that of the wave. Figure 1 consists of five consecutive traces superimposed, and it can be seen that the $F$ waven varies slightly in latency and waveform in differen $\mathbb{D}$. sweeps. When individual traces are inspected, it ap pears that several motor units, each of characteris $\frac{0}{3}$ tic waveform and latency, are contributing to the response. In Fig. 3, for example, the waveform an latency of the $F$ wave are similar in sweeps 3 and but different from those in sweeps 2 and 4; anothe response again is seen in sweep 5 , whereas sweep? 1,6 , and 8 show only low-voltage fluctuations of the trace. Figure 3 was taken from a patient with pathological lesion which may have exaggeratees: the asynchrony of conduction in different moto fibres, but a similar variability of latency has bee $\bar{P}$ observed in healthy subjects.

When the latency of the earliest component of the $F$ wave is measured in different individuals, is can be shown to be linearly related to the length of the arm. For the median and ulnar nerves, whe stimulated at the wrist, we have found the $F$ wave 
latency to vary from 24 to $32 \mathrm{msec}$. in healthy adults.

RESPONSES OF INTERMEDIATE LATENCY In patients with wasting of the muscles of the hand due to chronic partial denervation, stimulation of the median or ulnar nerve at the wrist has sometimes produced a muscle response with a latency intermediate between those of the $M$ and $F$ waves; such a response suggests the possibility of an axon reflex. An example of this is shown in Figs. 2 and 3, taken from a patient with a cervical rib and a wasted hand. It can be seen that between the $M$ and the $F$ wave there is a small potential (AR) which is apparently derived from a single motor unit, and which has a latency of approximately $20 \mathrm{msec}$. In Fig. 2, eight successive sweeps were superimposed whereas in 'Fig. 3 the trace was moved vertically between each stimulus so that successive responses could be examined individually; this illustrates the regularity of the potential AR, in contrast to the variable latency and waveform of the $F$ wave.

It might be asked why a potential such as that shown in Figs. 2 and 3 should not be a late component of the $M$ wave, due to slow conduction in pathological nerve between the wrist cathode and the muscle. This possibility was excluded by stimulating through a second cathode placed over the course of the nerve $3-4 \mathrm{~cm}$. proximal to the first cathode at the wrist. The effect of this procedure was to reduce the latency of the response, indicating that conduction was initially in a proximal and not in a distal direction. This is illustrated by the records in Figs. 4 and

- 5 taken from a patient with diabetic neuropathy and wasting of the hand. Figure 4 is a record taken with

- surface electrodes and shows the characteristic response AR between the $M$ and $F$ waves. In order

- to obtain Fig. 5 a coaxial needle was inserted into the same muscle and placed in such a position that the potential AR could be clearly identified. This - potential seemed to be derived from a single motor unit since it appeared suddenly at a fixed stimulus

- intensity, its waveform then remaining constant except when the recording needle was moved. From

$\checkmark$ the two sets of tracings in Fig. 5 it can be seen that when the stimulus was moved from $a$ to $b$ the latency

2 of the $\mathbf{M}$ wave increased, but that the reverse hap, pened to the potential AR, the latency of which was shortened by $3.5 \mathrm{msec}$.

Potentials with similar characteristics were identified in nine patients and their latencies are shown in Table I. From this table it can be seen that the latency was usually too short for an impulse to pass from the wrist to the spinal cord and back to the muscle; in such cases it can only be concluded that impulses initiated at the wrist ascended the arm for a certain

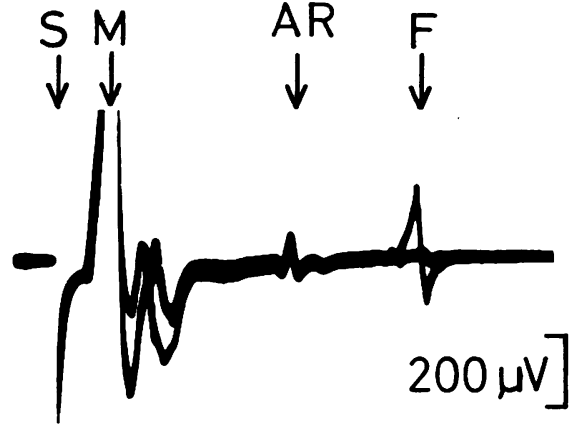

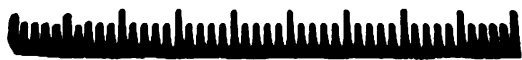
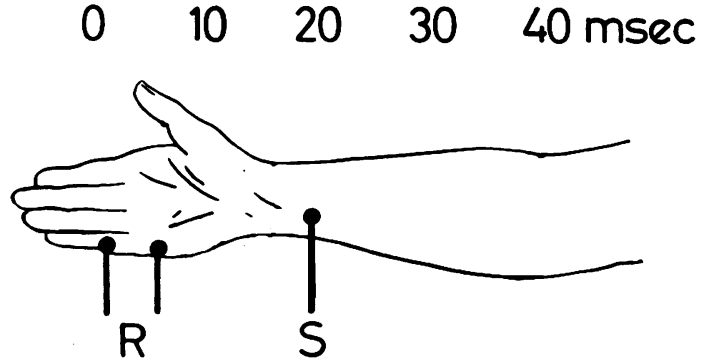

FIG. 2. Mr. J. B. Cervical rib syndrome. Muscle action potentials from abductor digiti minimi recorded through surface electrodes. In addition to $M$ and $F$ waves, a small potential $(A R)$ is present with a latency of 20 msec. Eight consecutive traces superimposed. The variation of the $M$ waveform from sweep to sweep is due to the fact that stimulus intensity was near threshold for some of the motor fibres in the ulnar nerve.

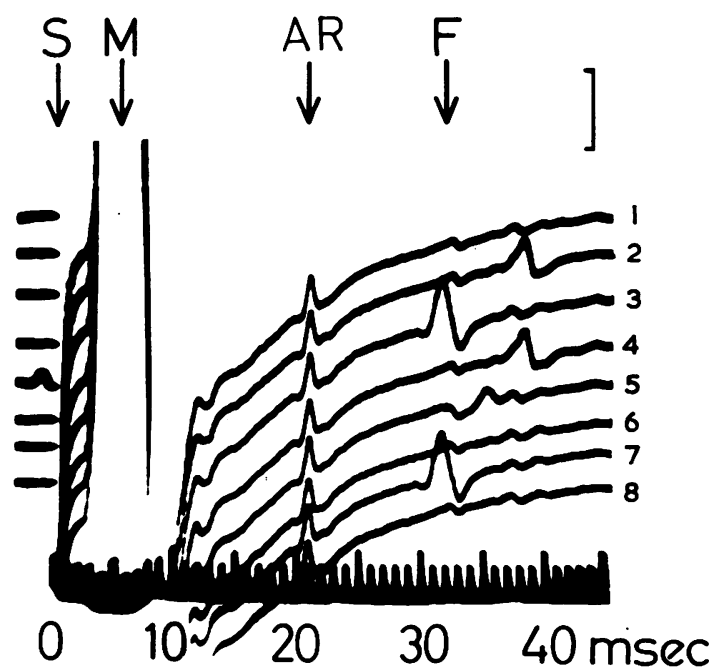

FIG. 3. As in Figure 2, but sweep moved vertically between stimuli to display individual traces. Calibration as in Figure 2. 

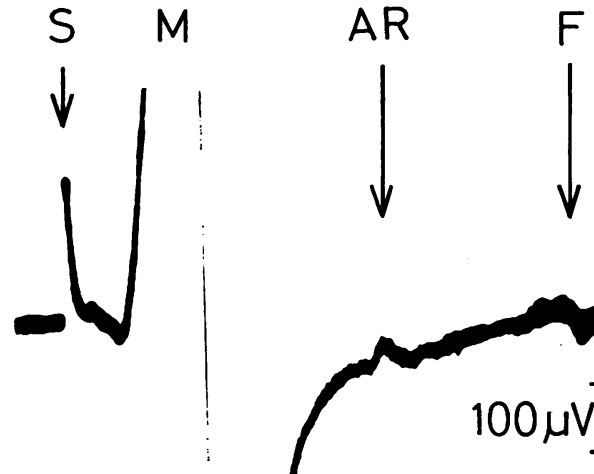

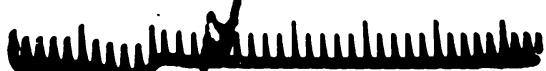
0 10 ? 20 $30 \mathrm{msec}$

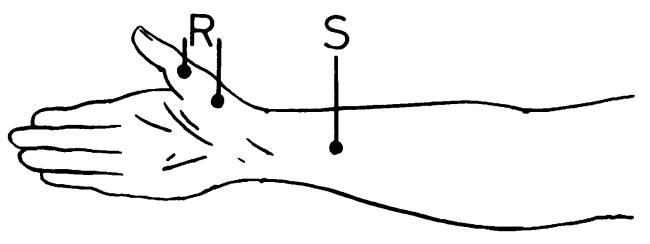

FIG. 4. Mr. B. L. Diabetic neuropathy. A potential AR is present between the $M$ and $F$ waves in the surface record from abductor pollicis brevis. Five consecutive traces superimposed.

distance and then returned to the muscle. In a few cases latencies were long enough to allow conduction to the spinal cord and back, assuming conduction velocity to be within the range $50-70 \mathrm{~m}$./ $\mathrm{sec}$. From Table I, however, it is clear that in such cases conduction velocity between the two stimulating

\begin{tabular}{|c|c|c|c|c|c|c|}
\hline \multirow{4}{*}{ Case } & \multicolumn{6}{|c|}{ TABLE I } \\
\hline & \multirow{3}{*}{$\begin{array}{l}\text { Hospital } \\
\text { No. }\end{array}$} & \multirow[t]{3}{*}{ Diagnosis } & \multirow{3}{*}{$\begin{array}{l}\text { Muscle } \\
\text { Examined }\end{array}$} & \multicolumn{3}{|c|}{ Axon Reflex } \\
\hline & & & & \multicolumn{2}{|c|}{ Latency (msec.) } & \multirow{2}{*}{$\begin{array}{l}\text { Velocity } \\
\text { (m./sec.) }\end{array}$} \\
\hline & & & & $\begin{array}{l}\text { Lower } \\
\text { Cathode }\end{array}$ & $\begin{array}{l}\text { Upper } \\
\text { Cathode }\end{array}$ & \\
\hline B.B. & A 9119 & Cervical rib & 1st DIO & $17 \cdot 0$ & $16 \cdot 2$ & $50 \cdot 0$ \\
\hline D.B. & A 2901 & Cervical rib & 1st DIO & $16 \cdot 2$ & $15 \cdot 4$ & \\
\hline J.B. & A 3385 & Cervical rib & ADM & $20 \cdot 1$ & $19 \cdot 5$ & $54 \cdot 2$ \\
\hline F.P. & 95923 & Cervical rib & 1st DIO & $21 \cdot 0$ & $19 \cdot 5$ & $26 \cdot 7$ \\
\hline R.E. & A 9922 & $\begin{array}{l}\text { Ulnar lesion } \\
\text { at elbow }\end{array}$ & ADM & $33 \cdot 7$ & $31 \cdot 2$ & $14 \cdot 0$ \\
\hline H.F. & A14481 & $\begin{array}{l}\text { Ulnar lesion } \\
\text { at elbow }\end{array}$ & 1st DIO & $29 \cdot 5$ & $27 \cdot 3$ & $18 \cdot 5$ \\
\hline R.H. & A 8492 & $\begin{array}{l}\text { Ulnar lesion } \\
\text { at elbow }\end{array}$ & ADM & $19 \cdot 1$ & $16 \cdot 3$ & $14 \cdot 3$ \\
\hline B.L. & A 10124 & Diabetes & APB & $\begin{array}{r}23 \cdot 8 \\
18.8\end{array}$ & $\begin{array}{l}20 \cdot 3 \\
17 \cdot 8\end{array}$ & $11 \cdot 4$ \\
\hline & A13749 & $\begin{array}{l}\text { Guillain- } \\
\text { Barré }\end{array}$ & ADM & $18 \cdot 8$ & $17 \cdot 8$ & $40 \cdot 0$ \\
\hline
\end{tabular}
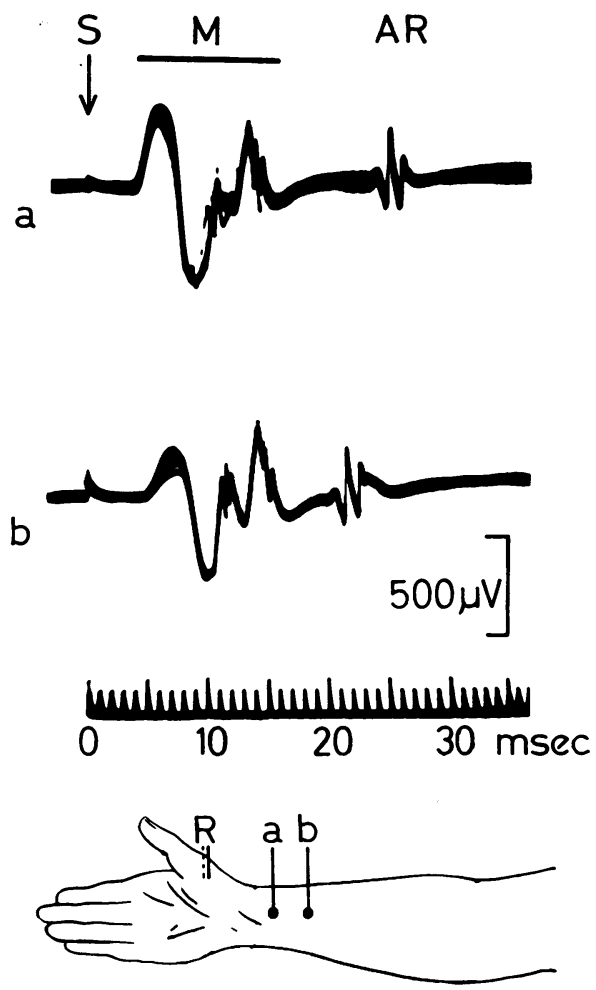

FIG. 5. As in Figure 4, but surface electrodes replaced coaxial needle. Latency of the potential $A R$ is longer stimulation through cathode a than cathode b. consecutive traces superimposed. Distance between cathodes a and b, $4 \mathrm{~cm}$.

cathodes was relatively slow; in the case illustrate in Fig. 5, for example, conduction velocity betweers $a$ and $b$ was $66.7 \mathrm{~m}$./sec. for the fastest componeng. of the $\mathrm{M}$ wave but only $11.4 \mathrm{~m}$. $/ \mathrm{sec}$. for the potentiat AR. Inspection of the velocities in Table I makes if. clear that in none of these cases cited would it have been possible for an impulse to have ascended to the spinal cord and returned to the muscle within the time available. On the other hand these finding could be simply explained by the presence of axo: branching at different levels in the forearm or arm?

EFFECT OF INCREASING STIMULUS INTENSITY I⿳⺈: searching for potentials due to axon reflexes ouf usual procedure was to record from the muscle: through surface electrodes, and to commence stimus: lating with the weakest shock that would produce $\overline{\mathbf{a}}$ : muscle response, stimulus intensity then being slowlos increased while particular attention was paid to that part of the trace between the $M$ and $F$ wavese In no case was an axon reflex seen with a stimulufs too weak to produce an $M$ wave, and it was onl 
with higher stimulus intensities that the characteristic potentials would appear. Each of these potentials seemed to be derived from a single motor unit, appearing abruptly at a certain stimulus intensity and then showing a constant waveform with stimulation at different sites along the nerve trunk; increasing stimulus intensity above the level necessary to produce a response did not alter the waveform up to a critical intensity at which the response suddenly disappeared.

This apparent abolition of the response by a strong shock, which was a characteristic feature of axon reflexes in records taken with surface electrodes, was easily explained when a coaxial needle was used for recording, as it was then possible to adjust the position of the needle so that the axon reflex response was larger than the $\mathbf{M}$ wave. When this was done it was clear that the effect of a strong shock was not to abolish the potential but to cause it to occur with a much shorter latency (Fig. 6).

In Fig. 6a a weak shock produced a small early deflection (the $M$ wave) followed by a large polyphasic potential with a latency of $17 \mathrm{msec}$. In Fig. $6 \mathrm{~b}$ stimulus intensity was slightly increased and it can be seen that out of five superimposed responses, four occurred at $17 \mathrm{msec}$. whereas one occurred at $9 \mathrm{msec}$. In Fig. $6 \mathrm{c}$ stimulus intensity was further increased with the result that all five responses occurred
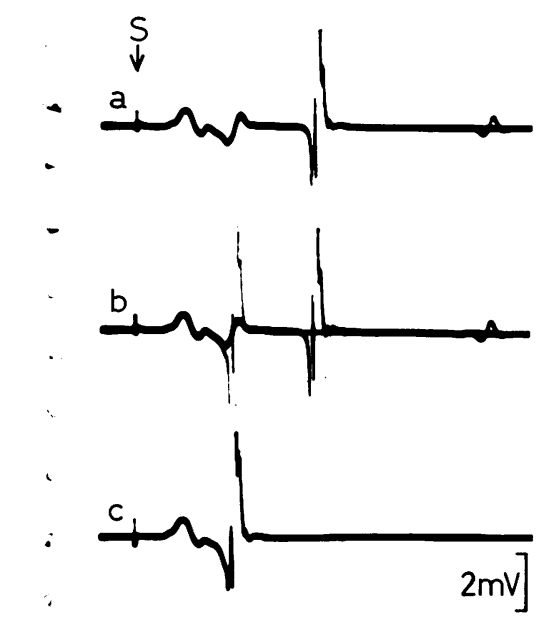

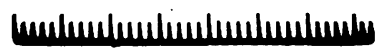

$\begin{array}{llll}0 & 10 & 20 & 30 \mathrm{msec}\end{array}$

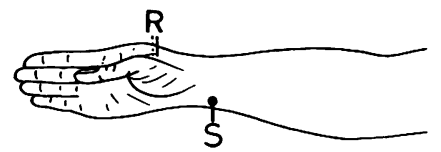

FIG. 6. Mrs. B. B. Cervical rib syndrome. Coaxial needle record from first dorsal interosseous muscle to show effect of increasing the stimulus to the ulnar nerve. Five successive traces superimposed. Stimulus intensity increased between $\mathrm{a}$ and $\mathrm{b}$ and further increased between $\mathrm{b}$ and $\mathrm{c}$. at $9 \mathrm{msec}$. This we interpret as meaning that in Fig. 6 a one of two axon branches was stimulated, resulting in an impulse which ascended to the point of branching and then passed down the other branch to the muscle, whereas in Fig. $6 \mathrm{c}$ the stronger shock was sufficient to excite both branches simultaneously, resulting in direct propagation from wrist to muscle (Fig. 7).

This interpretation was confirmed by further experiments in which conduction velocity was measured separately for the afferent and efferent branches of the reflex arc. Results from two patients are contained in Table II and illustrative records from one of them are shown in Figure 8. In this

TABLE II

\begin{tabular}{|c|c|c|c|c|c|}
\hline \multirow[t]{2}{*}{ Case } & \multirow{2}{*}{$\begin{array}{l}\text { Stimulus } \\
\text { Intensity } \\
\text { (volts) }\end{array}$} & \multicolumn{2}{|c|}{$\begin{array}{l}\text { Latency of } \\
\text { Response (msec.) }\end{array}$} & \multicolumn{2}{|c|}{ Velocity $(\mathrm{m} . / \mathrm{sec})}$. \\
\hline & & $\begin{array}{l}\text { Distal } \\
\text { Cathode }\end{array}$ & $\begin{array}{l}\text { Proximal } \\
\text { Cathode }\end{array}$ & Afferent & Efferent \\
\hline D.B. & $\begin{array}{l}100 \\
200\end{array}$ & $\begin{array}{r}16 \cdot 2 \\
6 \cdot 3\end{array}$ & $\begin{array}{r}15 \cdot 4 \\
8 \cdot 1\end{array}$ & $50 \cdot 0$ & $22 \cdot 2$ \\
\hline R.H. & $\begin{array}{l}120 \\
180\end{array}$ & $\begin{array}{r}19 \cdot 1 \\
7 \cdot 2\end{array}$ & $\begin{array}{r}16 \cdot 3 \\
9 \cdot 1\end{array}$ & $14 \cdot 3$ & $21 \cdot 0$ \\
\hline
\end{tabular}

patient it can be seen that with a stimulus intensity of $100 \mathrm{~V}$, conduction was initially in a proximal direction from the wrist, the latency of the response being $16.2 \mathrm{msec}$. for cathode $a$ and $15.4 \mathrm{msec}$. for cathode $b$, and conduction velocity between the two points of stimulation $50 \mathrm{~m}$./ $/ \mathrm{sec}$. When stimulus intensity was increased to $200 \mathrm{~V}$, the latency of the response shortened abruptly to $6 \cdot 3 \mathrm{msec}$. for cathode
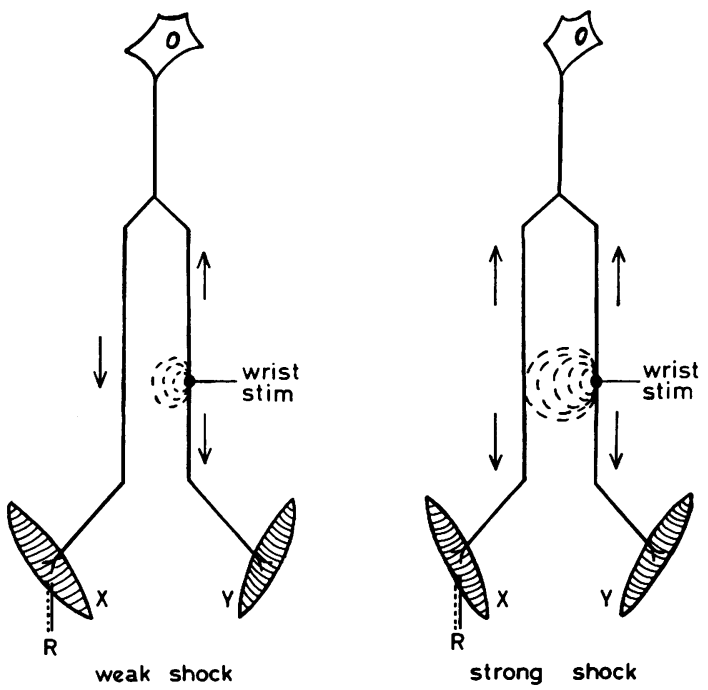

FIG. 7. Suggested mechanism of axon reflex. 


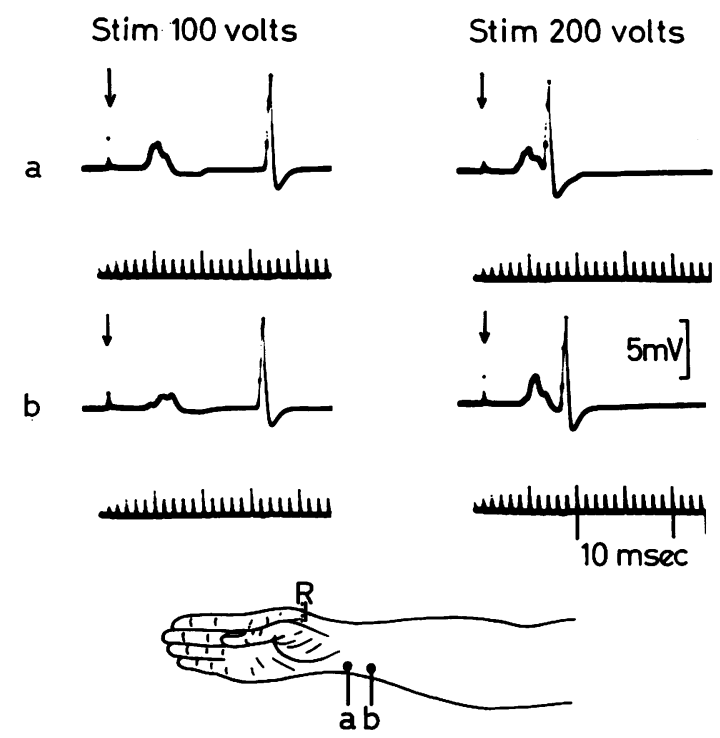

FIG. 8. Mrs. D. B. Cervical rib syndrome. Coaxial needle record from the first dorsal interosseous muscle to show the effect of weak and strong shocks to the ulnar nerve, when delivered through distal cathode a or proximal cathode b; distance between cathodes, $4 \mathrm{~cm}$.

$a$ and 8.1 msec. for cathode $b$; conduction from the point of stimulation was thus in a distal direction and at a velocity of $23.5 \mathrm{~m}$. $/ \mathrm{sec}$.

If both branches of the axon lie in the same nerve trunk at the wrist, it may be asked why an electrical stimulus through the skin should pick out one branch rather than the other? It might be argued that the branch with the higher conduction velocity would have the lower electrical threshold, as in the patient described above, but this is not necessarily so. Results from the other patient in Table II indicate that, although conduction velocity was reduced in both branches, it was in fact the branch with the slightly lower velocity which was more easily excited. In this case the anatomical position of the fibres in the nerve trunk was probably an important factor in determining which of the two branches would respond first to percutaneous stimulation.

THE SITE OF AXON BRANCHING The results shown in Table II illustrate another point of some importance. The patient R.H. had an ulnar nerve lesion at the elbow, and the distance from wrist to elbow was $25 \mathrm{~cm}$. Even if the higher of the two velocities given in Table II is accepted for conduction round the reflex arc, it can be calculated from the total conduction time that the site of branching cannot have been higher than the mid-forearm, although the lesion was at the elbow.
More direct evidence that branching might occur below the level of the lesion was obtained from the records shown in Figures 9 and 10. Both records were taken with a coaxial needle in the wasted first dorsal interosseous muscle of the patient D.B., and Fig. 9 shows the axon reflex response (AR) which appeared between the $M$ and $F$ waves when the ulnar nerve was stimulated at the wrist. The response AR is shown in greater detail in Fig. 10 a-d, the stimulus being applied at four different levels in the forearm and arm. In $a$ the stimulus was applied at the wrist, in $b 4 \mathrm{~cm}$. above the wrist; in $c$ the stimulus was applied at the elbow and in $d 4 \mathrm{~cm}$. higher still. It can be seen that when the stimulating cathode was moved from $a$ to $b$ the latency of the response AR grew shorter, whereas when the stimulus was moved from $c$ to $d$ the latency lengthened, from which it may be concluded that the branching of the motor fibre concerned was in the forearm between $b$ and $c$. This was confirmed by the observation that with stimulation through cathodes $a$ and $b$ the response AR disappeared when stimulus intensity was increased, whereas with stimulation through cathodes $c$ and $d$ the response was unaffected by increased stimulus intensity. Since the site of nerve damage in the patient D.B. was in the brachial plexus, thie्尺 provides a further example of axon branching below the level of the lesion. A similar result was obtained $\frac{\mathbb{D}}{0}$ in the patient B.B. for the axon reflex shown ing Figure 6.

Although the evidence is less conclusive than in the patients cited above, it also seems from the latencies and conduction velocities of the patient F.P. shown in Table $I$ that propagation from the wrist to the level of the lesion and back to the muscle is unlikely to have occurred within the time available. Thus, out of seven patients with localized lesions, there are four in whom the site of branching appears to have been substantially below the site of nerve damage.

THE TERMINATION OF AXON BRANCHES When aXon branching occurs in the proximal part of a motor nerve, it may be asked whether or not the two branches terminate close to each other in the same muscle. This question cannot be answered with certainty, but our results suggest that the terminations of the two branches may be widely separated in the same muscle or in different muscles.

It can be seen from the diagram in Fig. 7 that a weak shock would be expected to produce not only an axon reflex in branch $X$, but also a direct response in branch Y. If the muscle fibres innervated by branch $Y$ were close to those innervated by branch $X$, one would expect action potentials from both groups of muscle fibres to reach the recording electrode, so that the same stimulus would produce an early 

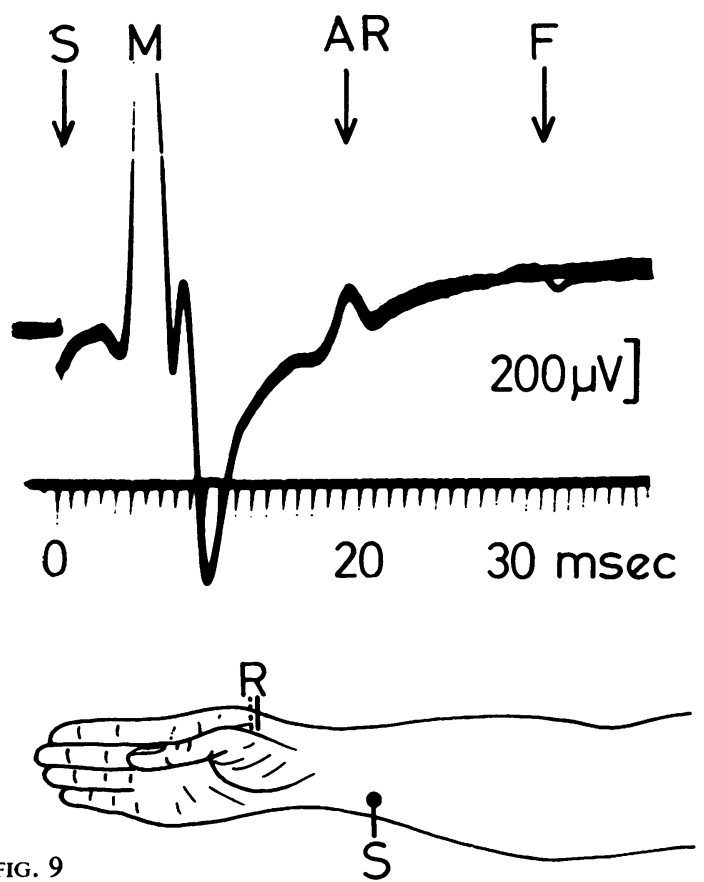

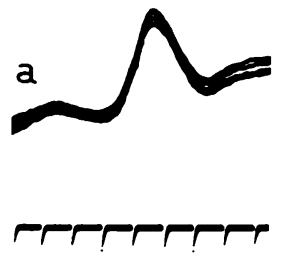

$\begin{array}{llll}16 & 18 & 20 & 22\end{array}$

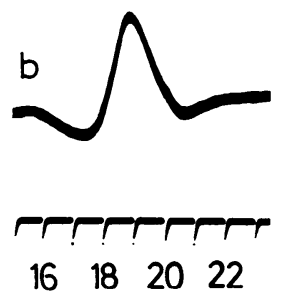

$\begin{array}{llll}16 & 18 & 20 & 22\end{array}$

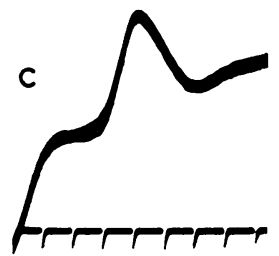

$1618 \quad 20 \quad 22 \mathrm{msec}$
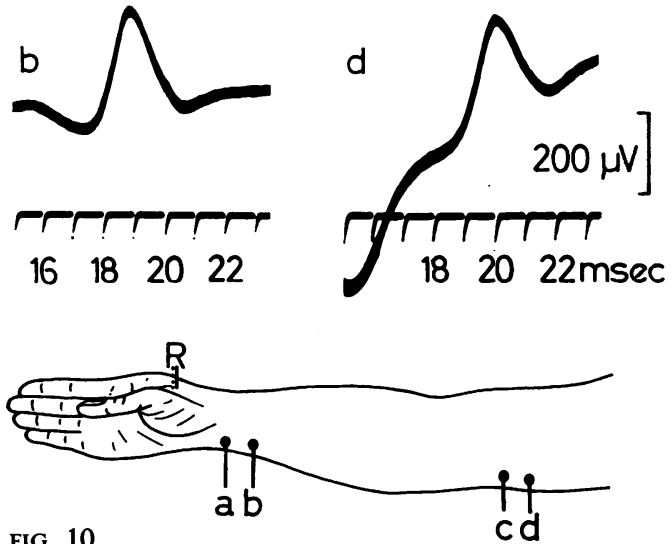

FIG. 9. Mrs. D. B. Cervical rib syndrome. Coaxial needle record from the first dorsal interosseous muscle to show potential $A R$ between $M$ and $F$ waves. Five consecutive traces superimposed.

FIG. 10. The potential AR from Figure 9 displayed on a fast sweep to show the effect of four stimulus positions on latency. Five successive traces superimposed. Latency shortened by moving stimulus from a to $\mathrm{b}$ but lengthened by moving from $\mathrm{c}$ to $\mathrm{d}$. Distance $\mathrm{a}-\mathrm{b}$ and $\mathrm{c}-\mathrm{d}, 4 \mathrm{~cm}$. in each case.

deflection due to activation of branch $Y$ and a late deflection due to branch $X$. The appearances of the early and late deflections in Figs. 6 and 8 might seem to be compatible with this, but the possibility is excluded by the results shown in Fig. 11, which is a record from the patient D.B. taken on the same occasion as Figure 8. In Fig. 11a the stimulating voltage was just below threshold and in Fig. 11b just above threshold for the axon reflex, but there is no change in the early deflection which must therefore be due to the activity of unrelated motor units.

Similar results were obtained from three other patients, from which it may be concluded that when an axon branches in its proximal part, the two branches do not usually terminate close enough to each other for the action potentials of both groups of muscle fibres to be recorded through the same coaxial needle electrode. Our results do not indicate whether the two branches usually supply different parts of the same muscle or whether they terminate in different muscles supplied by the same nerve.

THE EFFECT OF REPETITIVE STIMULATION In four patients the effect of repetitive stimulation at rates of 30 to 40 per second was studied. In each case the axon reflex was unaffected by three-second periods of stimulation at these frequencies.

In addition, paired shocks were used in three patients to determine the refractory period of the axon reflex. Both shocks were delivered to the ulnar nerve through a single wrist cathode, the stimulus intensity of each being $20-25 \%$ above threshold for the response. Stimulus intervals of $1 \cdot 0,2 \cdot 0$, and 3.0 msec. were used. Results were similar in the three patients; there was no response to the second shock when it was delivered $1 \mathrm{msec}$. after the first, but the response was present when the stimulus interval was 2 or $3 \mathrm{msec}$. At short intervals the presence or absence of a second response in a single fibre would be expected to depend upon stimulus intensity, a strong shock giving a response at a time when a weak one would fail to do so. In two of the patients it was not possible to increase stimulus intensity, as this caused the axon reflex to disappear altogether, but in the third patient the axon reflex could be obtained over a much wider range of stimulus intensity so that the effect of weak and strong shocks could be compared. 

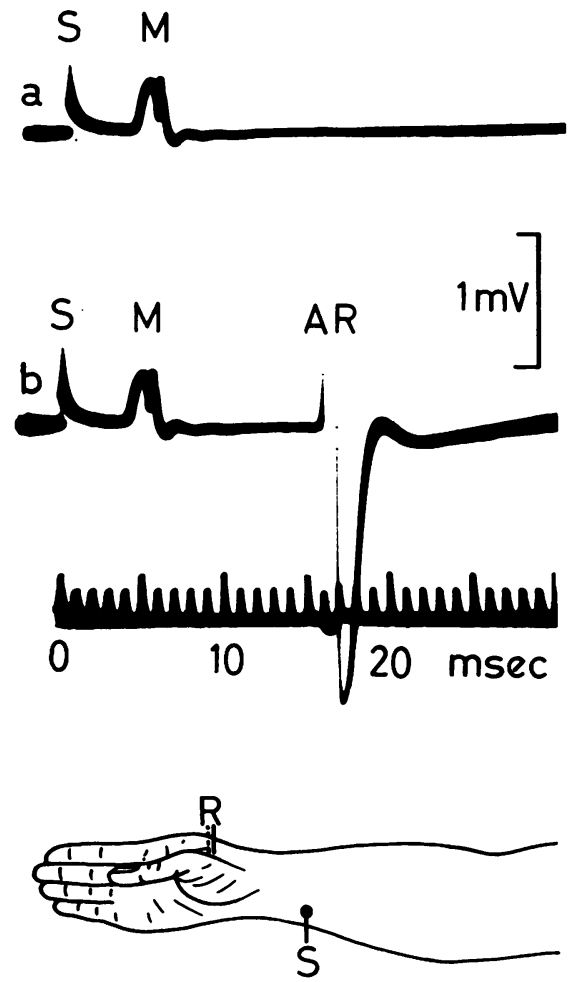

FIG. 11. Mrs. D. B. Cervical rib syndrome. Stimulus intensity in a is just below threshold and in $\mathrm{b}$ just above threshold for the potential AR. There is no change in the $M$ wave. Five consecutive traces superimposed.
The results of this procedure are illustrated in Fig. 12, which shows records taken with a coaxial needle electrode from the patient D.B. In Fig. 12a the intensity of $\mathbf{S} 2$ was similar to that of $\mathbf{S 1}$, both being 20 to $25 \%$ above threshold; it can be seen that there was no response to $\mathbf{S} 2$ when this was delivered $1 \mathrm{msec}$. after $\mathrm{S} 1$, although there was an axon reflex response (latency, $15.4 \mathrm{msec}$.) when either shock was delivered alone. Figure 12b shows that when the intensity of $\mathbf{S} 2$ was increased to between two and three times threshold, a second response was present at a stimulus interval of $1 \mathrm{msec}$. This response showed an increase in latency and a decrease in amplitude, presumably due to conduction in partially refractory nerve and muscle.

INCIDENCE OF AXON REFLEXES Responses due to axon reflexes were found in nine of the 25 patients examined (Table III). They were present in half of

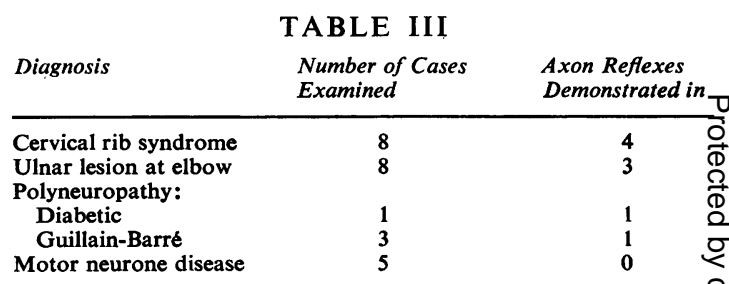

the patients with cervical ribs and polyneuropathy in three of the patients with ulnar nerve lesions, bufe in none of the patients with motor neurone disease: 
In two patients with ulnar nerve lesions and one patient with a cervical rib, action potentials probably due to axon reflexes were present; these potentials had typical latencies and showed the characteristic response to increasing stimulus intensity. However, the direction of propagation from the wrist could not be established and so thése cases have not been included with the positive results. In all the patients in whom axon reflexes were detected, symptoms had been present for at least nine months, whereas seven of the 16 patients in whom we failed to find such reflexes had symptoms of a shorter duration.

In 19 patients two or three muscles of the affected hand were studied at the same examination. In 12 patients the examinations were negative, but of the remainder three out of seven showed axon reflexes in more than one muscle. No general statement can be made concerning the number of axon reflexes in a single muscle since systematic exploration of different areas of the same muscle by both surface and needle electrodes was never attempted. In five patients, however, it was noted that when one axon reflex was being studied, other potentials were seen which showed similar features.

In six patients axon reflexes were found repeatedly in the same muscle at different examinations separated by intervals of a few weeks or months, one patient showing the phenomenon regularly on as many as four occasions over a period of six months. However, in one patient in whom an axon reflex was found at the first visit, re-examination of the same muscle was negative on a subsequent occasion.

\section{DISCUSSION}

Before accepting that the phenomena which have been described are due to axon reflexes, it should be asked whether they could be explained by any other mechanism. It has been demonstrated that impulses from the wrist ascend the arm but do not reach the spinal cord. Could repetitive firing in the proximal part of the nerve trunk be responsible for the longlatency responses which we have seen? This possibility can be excluded by reference to Figs. $6 a$ and $8 \mathrm{a}$, in which there is a small $M$ wave followed by a late potential of larger amplitude; from this it is clear that the muscle fibres giving rise to the late potential had not fired previously.

Artificial synapses have been described between damaged nerve fibres in the cat, with cross-excitation between one fibre and another (Granit and Skoglund, 1945). However, they are unlikely to have been responsible for our results for a number of reasons. The responses which we have studied have shown a constant latency and waveform in successive sweeps; they have followed rapid rates of stimulation without fatigue, and have been elicited by paired shocks at intervals of 1 or 2 msec. These properties are not those of artificial synapses and they must, we think, imply the presence of axon branching.

Anatomical evidence suggests that some branching occurs in the proximal parts of normal nerve fibres in both man and animals (Sunderland and Lavarack, 1953). In man, anatomical studies have been confined to the sensory nerves (Lavarack, Sunderland, and Ray, 1951), but in the cat Eccles and Sherrington (1930) have shown that branching also occurs in muscle nerves deprived of their afferent fibres by previous removal of the dorsal root ganglia. In these experiments the presence of branching was demonstrated by counting the total number of myelinated fibres in a de-afferentated nerve trunk at different distances from the muscle; branching was also demonstrated in teased preparations of single fibres.

However, when stimulating peripheral nerves in normal human subjects we have never obtained responses suggestive of axon branching. It might be argued that if the threshold of the two branches were the same, both would be excited by a single shock so that no axon reflex would result; such an explanation could be invoked to explain our failure to demonstrate axon reflexes in healthy subjects although they are easily found in pathological cases with altered nerve thresholds. This argument seems improbable on two counts; in the first place Eccles and Sherrington (1930) stated specifically that the two axon branches in their animals were often dissimilar in size; thus they might be expected to have different thresholds to electrical stimulation. In the second place the threshold of a human nerve fibre to percutaneous stimulation depends greatly on its anatomical position in the nerve trunk; if branching were a normal phenomenon one should sometimes be able to stimulate one branch without the other and thus produce an axon reflex, even if the two branches were of similar size. However, although we have recorded $\mathrm{M}$ and $\mathrm{F}$ waves from the small muscles of the hand in more than 20 healthy subjects, we have never seen anything comparable to the potentials found in patients with neuropathy, and which we regard as indicative of axon branching.

It is well recognized that fibres which are regenerating following nerve injury may branch at the site of the lesion. However, we have demonstrated in more than half of our patients that the site of branching was below the level of the lesion. The axon reflexes which we have observed might be due to branching at the tip of a regenerating nerve fibre distal to the site of injury or, alternatively, they might be due to collateral sprouting by normal surviving nerve fibres. 
Unfortunately, the present data do not enable us to decide between these alternatives.

Our failure to find axon reflexes in patients with motor neurone disease is of some relevance. If we were dealing with the terminal branching of regenerating axons at or below the level of a local lesion, we would not expect to find the phenomenon in conditions such as motor neurone disease or poliomyelitis. However, collateral sprouts arising in the forearm or arm would take many months to reach the periphery, and two of our five patients with motor neurone disease had short histories of rapidly progressive wasting; in such cases axon reflexes would not be expected on grounds of time alone. Further studies on patients with spinal muscular atrophy of long duration are clearly required before it can be decided whether or not collateral sprouts from surviving axons are likely to be responsible for axon branching of the type we have demonstrated.

The alternative theory, that branches are formed by terminal sprouting as the tips of regenerating axons grow towards the periphery, is supported by the work of Esslen (1960), who examined patients with traumatic peripheral nerve lesions and who was able to record the synchronous discharge of motor units in different muscles after reinnervation. One of his patients showed synchronous activity in orbicularis oculi and zygomaticus when examined 18 months after complete facial paralysis due to a head injury. Another patient showed synchronous activity in adductor pollicis and the second dorsal interosseous muscle, 14 months after suture of a divided ulnar nerve above the elbow. Although the presence of axon reflexes was not confirmed by electrical stimulation, Esslen's results suggest that axon branching had occurred during regeneration, resulting in the innervation of widely separated groups of muscle fibres by the same anterior horn cell.

\section{SUMMARY}

The muscle action potentials evoked by stimulation of the median or ulnar nerve at the wrist have been recorded from the small hand muscles of healthy subjects and patients with wasting due to chronic partial denervation.

In patients with partial denervation, impulses initiated by a shock at the wrist sometimes appeared to ascend the arm for a certain distance and then return to the hand, the muscle action potentials occurring after a delay which could be shortened by moving the stimulating cathode in a proximal direction from the wrist. This delay was, however, too short to allow conduction to the spinal cord and back; this suggests that branching had occurred in motor fibres in the arm, allowing impulses to ascend to the point of branching and then return via the other branch to the muscle.

Responses suggestive of axon branching were found in seven patients with local peripheral nerve lesions and in two patients with generalized peripheral neuropathy.

In four patients with localized lesions the site of axon branching appeared to be below the level of the lesion.

We wish to thank the Medical Research Council for a personal grant to one of us (P.M.F.). We are indebted to Dr. W. A. Cobb for providing facilities in the Department of Applied Electrophysiology and to Mr. H. B. Morton for technical assistance.

\section{REFERENCES}

Carpendale, M. T. F. (1956). Conduction time in the terminal portion of the motor fibres of the ulnar, median and peroneal nerves in healthy subjects and in patients with neuropathy. M.S. Thesis (Phys. Med.), University of Minnesota.

Causey, G., and Hoffman, H. (1955). Axon sprouting in partially deneurotized nerves. Brain, 78, 661-668.

Coërs, C. (1955). Aspects histologiques de la régénération neuromusculaire au cours de diverses affections du neurone moteur périphérique. Acta neurol. belg., 55, 23-30.

Scientific Publications, Oxford.

Dawson, G. D., and Merton, P. A. (1956). 'Recurrent' discharges from motoneurones. 20e Congr. int. Physiol., Bruxelles, 1956: Abstr. comm., pp. 221-222.

Ebeling, P., Gilliatt, R. W., and Thomas, P. K. (1960). A clinical and electrical study of ulnar nerve lesions in the hand. $J$. Neurol. Neurosurg. Psychiat., 23, 1-9.

Eccles, J. C., and Sherrington, C. S (1930). Numbers and contractionvalues of individual motor-units examined in some muscles of the limb. Proc. roy. Soc. B., 106, 326-357.

Edds, M. V. (1953). Collateral nerve regeneration. Quart. Rev. Biol., 28, 260-276.

Erminio, F., Buchthal, F., and Rosenfalck, P. (1959). Motor unit territory and muscle fiber concentration in paresis due to peripheral nerve injury and anterior horn cell involvement. Neurology (Minneap.), 9, 657-671.

Esslen, E. (1960). Electromyographic findings on two types of misdirection of regenerating axons. Electroenceph. clin. Neurophysiol., 12, 738-741.

Fullerton, P. M. (1963). The effect of ischaemia on nerve conduction in the carpal tunnel syndrome. J. Neurol. Neurosurg. Psychiat., 26, 385-397.

- (1964). Peripheral nerve conduction in metachromatic leucodystrophy (sulphatide lipidosis). Ibid., 27, 100-105.

Gilliatt, R. W., and Willison, R. G. (1963). The refractory and supernormal periods of the human median nerve. Ibid., 26, 136-147.

Granit, R., and Skoglund, C. R. (1945). Facilitation, inhibition and depression at the 'artificial synapse' formed by the cut end of a mammalian nerve. J. Physiol. (Lond.), 103, 435-448.

Harriman, D. (1961). Histology of the motor end-plate. In Electrodiagnosis and Electromyography, 2nd ed., edited by S. Licht, pp. 134-152. Licht, New Haven, Conn.

Hunt, C. C., and Kuffler, S. W. (1954). Motor innervation of skeletal muscle: multiple innervation of individual muscle fibres and motor unit function. J. Physiol. (Lond.), 126, 293-303.

Lavarack, J. O., Sunderland, S., and Ray, L. J. (1951). The branching of nerve fiber in human cutaneous nerves. J. comp. Neurol. 94, 293-311.

Magladery, J. W., and McDougal, D. B. (1950). Electrophysiological studies of nerve and reflex activity in normal man. Johns Hopk. Hosp. Bull., 86, 265-290. 
Nageotte, J. (1932). Sheaths of the peripheral nerves. Nerve degeneration and regeneration. In Cytology and Cellular Pathology of the Nervous System, edited by W. Penfield, vol. 1, pp. 189-239. Hoeber, New York.

Pitman, J. R. (1958). A digital delay and time-scale generator. $J$. Physiol. (Lond.), 142, 3-5P.

Ramón y Cajal, S. (1928). Degeneration and Regeneration of the Nervous System, vol. 1. Oxford University Press, London.

Shawe, G. D. H. (1955). On the number of branches formed by regenerating nerve-fibres. Brit. J. Surg., 42, 474-488.

Sunderland, S., and Lavarack, J. O. (1953). The branching of nerve fibres. Acta anat. (Basel), 17, 46-61.
Thomas, P. K. (1960). Motor nerve conduction in the carpal tunnel syndrome. Neurology (Minneap.), 10, 1045-1050.

Wiesendanger, M., and Gassel, M. M. (1964). The contribution of centrifugal backfiring to the ' $F$ wave'. Electroenceph. clin. Neurophysiol., 17, 103.

Wohlfart, G. (1955). Regenerative phenomena in the muscle nerves in connection with poliomyelitis and amyotrophic lateral sclerosis. Nord. Med., 54, 1075-1078.

- (1958). Collateral regeneration in partially denervated muscles. Neurology (Minneap.), 8, 175-180.

Yahr, M. D., Herz, E., Moldaver. J., and Grundfest, H. (1950). Electromyographic patterns in reinnervated muscle. Arch. Neurol. Psychiat., 63, 728-738. 